\title{
Brief report: attitudes towards Covid-19 vaccination among hospital employees in a tertiary care university hospital in Germany in December 2020
}

\author{
Stilla Bauernfeind ${ }^{1}$ (D) . Florian Hitzenbichler ${ }^{1} \cdot$ Gunnar Huppertz ${ }^{2} \cdot$ Florian Zeman $^{2} \cdot$ Michael Koller $^{2}$. \\ Barbara Schmidt ${ }^{3} \cdot$ Annelie Plentz $^{3} \cdot$ Markus Bauswein $^{3} \cdot$ Arno Mohr $^{4} \cdot$ Bernd Salzberger $^{1}$
}

Received: 19 March 2021 / Accepted: 27 April 2021 / Published online: 20 May 2021

(c) The Author(s) 2021

\begin{abstract}
Coronavirus disease 2019 (Covid-19) vaccination is essential to fight the pandemic. Health care workers (HCWs) are prioritized to get vaccinated, yet uptake of recommended vaccinations is known to be low in this group. In a tertiary care university hospital with a high number of Covid-19 patients in intensive care, $59.5 \%$ of surveyed staff $(N=2454)$ were willing to get vaccinated, $21.4 \%$ were unsure and $18.7 \%$ refused. Vaccine hesitancy was higher in female, younger and healthy employees without contact to Covid-19 patients; nurses (53.3\%) were much less willing to get vaccinated compared to physicians (82.7\%).
\end{abstract}

Keywords Covid-19 $\cdot$ Vaccination $\cdot$ Health care workers $\cdot$ Vaccine hesitancy

\section{Introduction}

Effective vaccines for SARS-CoV-2 have been rapidly developed. Vaccine acceptance will be a critical issue in mass vaccination. A population wide European survey [1] and an international survey [2] both predicted potential vaccine uptakes of about $70 \%$.

HCWs are at a high risk for infection with severe acute respiratory syndrome coronavirus 2 (SARS-CoV-2) and can be a source of transmission to patients and colleagues. Major hospital outbreaks were reported in 2003 and during the current coronavirus pandemic $[3,4]$. Nevertheless, uptake of recommended vaccines among HCWs in general is low

Stilla Bauernfeind

stilla.bauernfeind@ukr.de

1 Department of Hospital Hygiene and Infectious Diseases, University Hospital Regensburg, Franz-Josef-Strauß-Allee 11, 93053 Regensburg, Germany

2 Center for Clinical Studies, University Hospital Regensburg, Franz-Josef-Strauß-Allee 11, 93053 Regensburg, Germany

3 Institute for Clinical Microbiology and Hygiene, University Hospital Regensburg, Franz-Josef-Strauß-Allee 11, 93053 Regensburg, Germany

4 Center for Pneumology, Donaustauf Hospital, Ludwigstraße 68, 93093 Donaustauf, Germany
[5]. Influenza vaccination coverage among HCWs in Europe is less than $30 \%$ [6].

University Hospital Regensburg is a tertiary care hospital and the only university hospital in a region in south-east Germany with a high rate of intensive care beds. Since the beginning of the pandemic, 247 Covid-19 patients have been cared for in the intensive care unit, about one third of them on extracorporeal membrane oxygenation (hospital data, April 2021).

In this context, understanding the local attitudes towards vaccination and identifying potential determinants of vaccine hesitancy are essential to effectively encourage vaccine uptake and protect both staff and patients.

\section{Methods}

We conducted a cross sectional survey to study the attitude of hospital employees towards Covid-19 vaccination from December 12th to $21 \mathrm{st}, 2020$. At this time, the mRNA vaccine BNT162b2 from BioNTech/Pfizer was on the verge of authorization in the European Union as its first Covid-19 vaccine and intended to be used in our institution.

Each hospital employee was offered a paper ticket that provided access to an online survey (Table S1, Supplementary Appendix). A ticket contained both a unique QR-Code 
and a unique access code for the survey website. The survey could have been completed either with an electronic device via QR-Code-App or by directly accessing the website, thus ensuring anonymity of the participants and preventing multiuse by anti-vaccinationists.

We defined health care workers as all our hospital employees, including clinical administrative staff and further personnel without patient contact or exposure to infectious materials. The hierarchy of vaccine prioritization among different groups of health care personnel is considered in the analysis.

The survey was programmed in REDCap, a web-based clinical data management system. Statistical analysis was performed using Stata 16 (StataCorp). Data are presented as absolute and relative frequencies. Predictors for vaccine acceptance (no vs. unsure and no vs. yes) were analyzed using logistic regression models generating odds ratios (OR). The 95\% confidence interval (CI) was used to estimate the precision of the OR.

The study was approved by the local Ethics Committee (Ref. number: 20-2141-101) as well as by the local data protection officer.

\section{Results}

A total of 4861 tickets were distributed. 2454 employees $(50.5 \%)$ completed the survey. The majority was female $(68.0 \%)$ and younger than 45 years (57.2\%). Most of the participants completed professional training (62.5\%), about one-third had a university degree. $23.7 \%$ had comorbidities that-according to their self-assessment-put them at an increased risk for a severe course of Covid- 19.

$25.6 \%$ of participants were nurses, $17.2 \%$ physicians and $13.7 \%$ held other positions with patient contact. $43.4 \%$ of participants had no immediate patient contact at work, including administrative, laboratory and technical staff.

$49.4 \%$ of survey participants reported to be in contact with Covid-19 patients at work. $29.2 \%$ indicated an occasional contact, whereas $20.2 \%$ had a regular contact defined by working on Covid-19 wards or in the emergency department. (Table 1).

During the current influenza season, $54.0 \%$ of survey participants received a flu shot, compared to $41.8 \%$ during the last influenza season 2019/2020.

As the authorization of BNT162b2, the first Covid-19 vaccine for Europe, was pending, we asked whether employees would be willing to get this vaccine. 59.9\% reported yes, $21.4 \%$ were unsure and $18.7 \%$ refused.

The most important argument for those who refused or were unsure (985 participants) was that the vaccine was not sufficiently tested (780 participants-79.2\%). Those bringing forward the argument of insufficient vaccine testing
Table 1 Participant characteristics

\begin{tabular}{ll}
\hline Variable & Total $(\%)$ \\
& $N=2454$ \\
\hline Demographic and individual factors & \\
Age group (years) & $190(7.7)$ \\
$\quad<25$ & $637(26.0)$ \\
$25-34$ & $577(23.5)$ \\
$35-44$ & $624(25.4)$ \\
$45-54$ & $426(17.4)$ \\
$\geq 55$ & \\
Gender & $783(31.9)$ \\
Male & $1668(68.0)$ \\
Female & $3(0.1)$ \\
Divers & \\
Education & $51(2.1)$ \\
High school & $1150(46.9)$ \\
Professional training & $382(15.6)$ \\
Advanced professional training & $869(35.4)$ \\
University & \\
Risk for a severe course of Covid-19 & $1501(61.2)$ \\
No & $372(15.2)$ \\
Unsure & $581(23.7)$ \\
Yes & $496(29.2)$ \\
Occupational factors & \\
Occupation & \\
Nurse & \\
Physician & \\
Other occupation with direct patient contact* & \\
Other occupation without direct patient contact** & $1065(437.4)$ \\
Direct contact with Covid-19 patients at work & \\
No & \\
Occasionally & \\
Regularly & \\
\hline
\end{tabular}

*e.g. physiotherapists, radiological technologists, social workers, dieticians

***e.g. laboratory assistance, pharmacists, researchers, administrative staff

would have accepted a non-mRNA based vaccine in $11.7 \%$, whereas, $47.6 \%$ of them hesitated and $40.8 \%$ also refused any other vaccine (data not shown).

Among other reasons for refusing were that participants did not feel well informed about the vaccinations (9.9\%), regarded themselves as not at risk through Covid-19 (2.7\%), reported a history of SARS-CoV-2 infection or had an attitude against vaccinations in general (1.2\%, each) (Table 2).

Vaccine acceptance was significantly higher in older age groups, $72.3 \%$ of those $\geq 55$ years would have taken the vaccine compared to $52.4 \%$ of those $<35$ years. In univariate logistic regression vaccine acceptance was associated with gender (females were more likely to refuse, OR 0.4, 95\% CI 0.3-0.5) and self-assessment of being at increased risk 
Table 2 Attitudes towards vaccination

\begin{tabular}{ll}
\hline Variable & Total $(\%)$ \\
& $N=2454$ \\
\hline Acceptance of BNT162b2 BioNTech/Pfizer mRNA vaccine \\
No & $459(18.7)$ \\
Unsure & $526(21.4)$ \\
Yes & $1469(59.9)$ \\
Reasons for refusal & \\
Vaccine not sufficiently tested & $780(79.2)$ \\
Not well-informed & $98(9.9)$ \\
Not at risk through Covid-19 & $27(2.7)$ \\
History of SARS-CoV-2 infection & $12(1.2)$ \\
Attitude against vaccinations in general & $12(1.2)$ \\
Fear of injections & $6(0.6)$ \\
Other & $50(5.1)$ \\
Flu shot in influenza season 2019/2020 & \\
No & $1429(58.2)$ \\
Yes & $1025(41.8)$ \\
Flu shot in influenza season 2020/2021 & \\
No & $1129(46.0)$ \\
Yes & $1325(54.0)$ \\
\hline
\end{tabular}

for a severe course of Covid-19 (OR 3.8, 95\% CI 2.8-5.3). Considering education, highest acceptance rates were seen in both employees without any professional training (60.8\%) and university graduates (74.3\%). Consequently, physicians were more likely to accept a Covid-19 vaccine compared to nurses (OR 5.5, 95\% CI 3.6-8.5). Another promotive factor was risk exposure. Those who had an occasional (OR $1.4,95 \%$ CI 1.1-1.7) or regular (OR 1.9, 95\% CI 1.4-2.5) contact with Covid-19 patients were significantly more likely to accept the vaccine than those without any Covid19 patient contact. Finally, employees willing to receive flu shots were more likely to accept a Covid-19 vaccine (OR 5.1, 95\% CI 3.9-6.6 last season, OR 7.9, 95\% CI 6.1-10.1 current season).

Regarding those unsure whether they should get vaccinated against Covid-19 (526 participants), there were no statistically significant differences found in most variables compared to those who completely refused. Only employees who considered themselves at risk for a severe course of Covid-19 and those who had received flu shots during the past two years were significantly more likely to accept the vaccine (Table 3 ).

\section{Discussion}

Vaccines are regarded as essential to overcome the SARS-CoV-2 pandemic. The development of herd immunity through vaccination depends on virus, vaccine and population factors [7]. Most importantly, people should be willing to get vaccinated. Yet vaccine hesitancy is a growing problem and has been described as a threat to global health in 2019 by the World Health Organization. Its determinants are complex and context-specific and vary across time, place and vaccines [8].

HCWs are at the frontline of Covid-19 response. Vaccination is especially recommended to protect them during occupational exposure and to prevent the spread of the disease.

In December 2020, shortly before the vaccination campaign started, $59.9 \%$ of our hospital employees were willing to get vaccinated with BNT162b2, 21.4\% were unsure and $18.7 \%$ refused.

Covid-19 vaccine acceptability surveys in health care personnel are rare. Those available are from different health care system backgrounds, assess varying groups of HCWs and are conducted at various stages of the pandemic. These are only some factors that make comparison difficult.

During the first wave of the pandemic in March and April 2020 vaccine acceptance rates ranging from $27.7 \%$ in Congolese HCWs to $78.1 \%$ in Israeli doctors were reported [9].

In a survey among general practitioners and nurses in France and French-speaking parts of Belgium and Canada conducted in October/November 2020, 72.4\% were in favor of getting vaccinated [10]. Among HCWs in the United States (staff working in healthcare settings regardless of patient care or contact) surveyed during the same period, $36 \%$ were willing to take the vaccine as soon as it became available while $56 \%$ were not sure or wanted to wait [11]. Similarly, among Los Angeles HCWs surveyed from September to December 2020, most participants (65.5\%) would have delayed vaccination [12].

Receptivity predictors that could be identified in HCWs in our study and elsewhere were perceived risk or exposure and being older, male or a doctor. Previous vaccination history was also associated with acceptance of a Covid-19 vaccine [13]. Regarding influenza vaccination, Hong Kong nurses showed a similar acceptance rate of seasonal influenza vaccination in 2019 and 2020 [14], whereas, our HCWs were much more willing to get vaccinated against influenza this year.

Nurses should be addressed especially in HCW vaccination campaigns. They have a high occupational risk and are often reluctant to get vaccinated. In our hospital, only $53.3 \%$ of nurses would have accepted the vaccine compared to $82.7 \%$ of physicians. Uncertainty is a big obstacle; information should be provided on safety and efficacy. Furthermore, the value and necessity of immunization should be emphasized.

Hospitals were not successful in achieving high uptakes of recommended vaccinations for HCWs which is especially evident for influenza. By identifying local attitudes and barriers to vaccination, campaigns can be started to strengthen 
Table 3 Covid-19 vaccine acceptance

\begin{tabular}{|c|c|c|c|c|c|}
\hline \multirow[t]{3}{*}{ Variable } & \multirow{3}{*}{$\begin{array}{l}\text { No } \\
\text { Total }(\%) \\
N=459\end{array}$} & \multicolumn{4}{|c|}{$\begin{array}{l}\text { Covid-19 vaccine acceptance }(N=2454) \\
\text { Reference: no acceptance }\end{array}$} \\
\hline & & \multicolumn{2}{|l|}{ Unsure } & \multicolumn{2}{|l|}{ Yes } \\
\hline & & $\begin{array}{l}\text { Total }(\%) \\
N=526\end{array}$ & $\begin{array}{l}\text { crude OR } \\
(95 \% \mathrm{CI})\end{array}$ & $\begin{array}{l}\text { Total }(\%) \\
N=1469\end{array}$ & $\begin{array}{l}\text { crude OR } \\
(95 \% \mathrm{CI})\end{array}$ \\
\hline & \multicolumn{5}{|c|}{ Demographic and individual factors } \\
\hline \multicolumn{6}{|l|}{ Age group (years) } \\
\hline$<25$ & $46(24.2)$ & $63(33.2)$ & Reference & $81(42.6)$ & Reference \\
\hline $25-34$ & $150(23.5)$ & $135(21.2)$ & $0.7(0.4-1.0)$ & $352(55.3)$ & $1.3(0.9-2.0)$ \\
\hline $35-44$ & $113(19.6)$ & $121(21.0)$ & $0.8(0.5-1.2)$ & $343(59.4)$ & $1.7(1.1-2.6)$ \\
\hline $45-54$ & $112(17.9)$ & $127(20.4)$ & $0.8(0.5-1.3)$ & $385(61.7)$ & $2.0(1.3-3.0)$ \\
\hline$\geq 55$ & $38(8.9)$ & $80(18.8)$ & $1.5(0.9-2.6)$ & $308(72.3)$ & $4.6(2.8-7.6)$ \\
\hline \multicolumn{6}{|l|}{ Gender } \\
\hline Male & $90(11.5)$ & $98(12.5)$ & Reference & $595(76.0)$ & Reference \\
\hline Female & $368(22.1)$ & $426(25.5)$ & $1.1(0.8-1.5)$ & $874(52.4)$ & $\mathbf{0 . 4}(0.3-0.5)$ \\
\hline Divers & $1(33.3)$ & $2(66.7)$ & $1.8(0.2-20.6)$ & 0 & n.d \\
\hline \multicolumn{6}{|l|}{ Education } \\
\hline High school & 10 (19.6) & 10 (19.6) & Reference & $31(60.8)$ & Reference \\
\hline Professional training & $268(23.3)$ & $313(27.2)$ & $1.2(0.5-2.9)$ & $569(49.5)$ & $0.7(0.3-1.4)$ \\
\hline $\begin{array}{l}\text { Advanced } \\
\text { professional training }\end{array}$ & $85(22.3)$ & $76(19.9)$ & $0.9(0.4-2.3)$ & $221(57.9)$ & $0.8(0.4-1.8)$ \\
\hline University & $96(11.1)$ & $127(14.6)$ & $1.3(0.5-3.3)$ & $646(74.3)$ & $2.2(1.0-4.6)$ \\
\hline \multicolumn{6}{|c|}{ Risk for a severe course of Covid-19 } \\
\hline No & $360(24.0)$ & $346(23.1)$ & Reference & $795(53.0)$ & Reference \\
\hline Unsure & $48(12.9)$ & $82(22.0)$ & $1.8(1.2-2.6)$ & $242(65.1)$ & $2.3(1.6-3.2)$ \\
\hline Yes & $51(8.8)$ & $98(16.9)$ & $2.0(1.4-2.9)$ & $432(74.4)$ & $3.8(2.8-5.3)$ \\
\hline \multicolumn{6}{|l|}{ Occupational factors } \\
\hline \multicolumn{6}{|l|}{ Occupation } \\
\hline Nurse & $142(22.6)$ & $152(24.2)$ & Reference & $335(53.3)$ & Reference \\
\hline Physician & $27(6.4)$ & $46(10.9)$ & $1.6(0.9-2.7)$ & $350(82.7)$ & $\mathbf{5 . 5}(3.6-8.5)$ \\
\hline $\begin{array}{l}\text { Other occupation } \\
\text { with direct } \\
\text { patient contact* }\end{array}$ & $70(20.8)$ & $85(25.2)$ & $1.1(0.8-1.7)$ & $182(54.0)$ & $1.1(0.8-1.6)$ \\
\hline $\begin{array}{l}\text { Other occupation } \\
\text { without direct } \\
\text { patient contact** }\end{array}$ & $220(20.7)$ & $243(22.8)$ & $1.0(0.8-1.4)$ & $602(56.5)$ & $1.2(0.9-1.5)$ \\
\hline \multicolumn{6}{|c|}{ Direct contact with Covid-19 patients at work } \\
\hline No & $266(21.4)$ & $284(22.9)$ & Reference & $692(55.7)$ & Reference \\
\hline Occasionally & $125(17.5)$ & $148(20.7)$ & $1.1(0.8-1.5)$ & $443(61.9)$ & $1.4(1.1-1.7)$ \\
\hline Regularly & $68(13.7)$ & $94(19.0)$ & $1.3(0.9-1.9)$ & $334(67.3)$ & $1.9(1.4-2.5)$ \\
\hline \multicolumn{6}{|c|}{ Attitude towards vaccination } \\
\hline \multicolumn{6}{|c|}{ Flu shot in influenza season 2019/2020 } \\
\hline No & $374(26.2)$ & $373(26.1)$ & Reference & $682(47.7)$ & Reference \\
\hline Yes & $85(8.3)$ & $153(14.9)$ & $1.8(1.3-2.4)$ & $787(76.8)$ & $5.1(3.9-6.6)$ \\
\hline \multicolumn{6}{|c|}{ Flu shot in influenza season $2020 / 2021$} \\
\hline No & $360(31.9)$ & $304(26.9)$ & Reference & $465(41.2)$ & Reference \\
\hline Yes & $99(7.5)$ & $222(16.8)$ & $2.7(2.0-3.5)$ & $1004(75.8)$ & $7.9(6.1-10.1)$ \\
\hline
\end{tabular}

Significant ORs (95\% CI) are presented in bold face; sum row $=100 \%$ 
confidence and so increase uptake of Covid-19 vaccines. This survey actually served as first sensitizing our hospital staff for the SARS-CoV-2 vaccination. It was followed by written and audiovisual information from our infectious diseases specialist and virologist presented on intranet. Vaccine acceptance finally exceeded survey results both in physicians and nursing staff (ongoing process, data not shown).

\section{Limitations}

This survey is subject to limitations. It is local data that cannot be applied to other places. It is a snapshot depicting staff's attitude just before vaccinations started in our hospital. Finally, as we were waiting for BNT162b2, this study is limited to the uptake of an mRNA vaccine with a German company involved in the development. Nevertheless, the present study may serve as a benchmark to set results into perspective from follow-up studies in our center and studies generated in other centers.

Supplementary Information The online version contains supplementary material available at https://doi.org/10.1007/s15010-021-01622-9.

Funding Open Access funding enabled and organized by Projekt DEAL. None (all authors).

\section{Declarations}

Conflicts of interest Bernd Salzberger: participates in advisory boards (GSK and SANOFI), lecture fees from Falk Foundation.

Florian Hitzenbichler: travel grants from Gilead Sciences, lecture fees from MSD.

Arno Mohr: travel grants from Gilead Sciences.

Open Access This article is licensed under a Creative Commons Attribution 4.0 International License, which permits use, sharing, adaptation, distribution and reproduction in any medium or format, as long as you give appropriate credit to the original author(s) and the source, provide a link to the Creative Commons licence, and indicate if changes were made. The images or other third party material in this article are included in the article's Creative Commons licence, unless indicated otherwise in a credit line to the material. If material is not included in the article's Creative Commons licence and your intended use is not permitted by statutory regulation or exceeds the permitted use, you will need to obtain permission directly from the copyright holder. To view a copy of this licence, visit http://creativecommons.org/licenses/by/4.0/.

\section{References}

1. Neumann-Böhme S, Varghese NE, Sabat I, Barros PP, Brouwer W, van Exel J, et al. Once we have it, will we use it? A European survey on willingness to be vaccinated against COVID-19. Eur J Health Econ. 2020;21:977-82. https://doi.org/10.1007/ s10198-020-01208-6.

2. Lazarus JV, Ratzan SC, Palayew A, Gostin LO, Larson HJ, Rabin K, et al. A global survey of potential acceptance of a COVID-19 vaccine. Nat Med. 2020. https://doi.org/10.1038/ s41591-020-1124-9.

3. Lee N, Hui D, Wu A, Chan P, Cameron P, Joynt GM, et al. A major outbreak of severe acute respiratory syndrome in Hong Kong. N Engl J Med. 2003;348:1986-94. https://doi.org/10.1056/ NEJMoă85.

4. Asad H, Johnston C, Blyth I, Holborow A, Bone A, Porter L, et al. Health care workers and patients as Trojan horses: a COVID19 ward outbreak. Infect Prevent Pract. 2020;2:100073. https://doi. org/10.1016/j.infpip.2020.100073.

5. Tuckerman JL, Collins JE, Marshall HS. Factors affecting uptake of recommended immunizations among health care workers in South Australia. Hum Vaccin Immunother. 2015;11:704-12. https://doi.org/10.1080/21645515.2015.1008886.

6. Dini G, Toletone A, Sticchi L, Orsi A, Bragazzi NL, Durando P. Influenza vaccination in healthcare workers: a comprehensive critical appraisal of the literature. Hum Vaccin Immunother. 2018;14:772-89. https://doi.org/10.1080/21645515.2017.13484 42.

7. Anderson RM, Vegvari C, Truscott J, Collyer BS. Challenges in creating herd immunity to SARS-CoV-2 infection by mass vaccination. Lancet. 2020;396:1614-6. https://doi.org/10.1016/S01406736(20)32318-7.

8. MacDonald NE. Vaccine hesitancy: definition, scope and determinants. Vaccine. 2015;33:4161-4. https://doi.org/10.1016/j.vacci ne.2015.04.036.

9. Sallam M. COVID-19 vaccine hesitancy worldwide: a concise systematic review of vaccine acceptance rates. Vaccines (Basel). 2021. https://doi.org/10.3390/vaccines9020160.

10. Verger P, Scronias D, Dauby N, Adedzi KA, Gobert C, Bergeat $\mathrm{M}$, et al. Attitudes of healthcare workers towards COVID-19 vaccination: a survey in France and French-speaking parts of Belgium and Canada, 2020. Euro Surveill. 2021. https://doi.org/10.2807/ 1560-7917.ES.2021.26.3.2002047.

11. Shekhar R, Sheikh AB, Upadhyay S, Singh M, Kottewar S, Mir H, et al. COVID-19 vaccine acceptance among health care workers in the United States. Vaccines (Basel). 2021. https://doi.org/10. 3390/vaccines9020119.

12. Gadoth A, Halbrook M, Martin-Blais R, Gray A, Tobin NH, Ferbas KG, et al. Cross-sectional assessment of COVID-19 vaccine acceptance among health care workers in Los Angeles. Ann Intern Med. 2021. https://doi.org/10.7326/M20-7580.

13. Lin C, Tu P, Beitsch LM. Confidence and receptivity for COVID19 vaccines: a rapid systematic review. Vaccines (Basel). 2020. https://doi.org/10.3390/vaccines9010016.

14. Wang K, Wong ELY, Ho KF, Cheung AWL, Chan EYY, Yeoh EK, Wong SYS. Intention of nurses to accept coronavirus disease 2019 vaccination and change of intention to accept seasonal influenza vaccination during the coronavirus disease 2019 pandemic: a cross-sectional survey. Vaccine. 2020;38:7049-56. https://doi. org/10.1016/j.vaccine.2020.09.021. 